\title{
Exploring the relationship between environmental stressors, pharmacy residents' stress and medication errors.
}

\author{
Hung M Le ${ }^{1 *}$, Shardae D Young ${ }^{2}$ \\ ${ }^{1}$ Department of Pharmacy, VA Texas Valley Coastal Bend Health Care System, Texas, USA \\ ${ }^{2}$ Department of Pharmacy, William S. Middleton Memorial Veterans Hospital, Wisconsin, USA
}

\begin{abstract}
Purpose: To explore the relationship between perceived stress, environmental stressors, and self-reported medication errors for PGY1 and PGY2 pharmacy residents.

Methods: A cross-sectional study design. An online questionnaire survey was sent to pharmacy residency program directors asking residents to participate. The primary objective is to evaluate the correlation between the 10-item Perceived Stress Scale (PSS-10), self-reported medication errors among pharmacy residents, and the impact of environmental stressors on the perceived stress.

Results: 524 pharmacy residents were included in the study. Pharmacy residents exhibiting high levels of Perceived stress scores reported high medication errors $(\mathbf{p}<0.001)$. Environmental stressors such as Time and Workload, Support, Personal, Career and Health were significant contributing factors to overall perceived stress.

Conclusion: There is a positive relationship between stress levels and medication errors reported by pharmacy residents. Several environmental stressors contribute to their stress and medication errors. Further research is needed to validate the role of stress on medication errors in pharmacy residents.
\end{abstract}

Keywords: Pharmacy residents, Perceived stress, Medication errors, Environmental stressors.

Accepted on September 11, 2017

\section{Introduction}

A national survey of pharmacists by Mott and colleagues found more than $70 \%$ of pharmacists experienced stress in the workplace. The most common environmental factors that contribute to their stress were interruptions by phone calls, heavy workloads, and long work hours [1]. A study conducted at two large US pediatric teaching hospitals revealed that pharmacists and pharmacy technicians reported high levels of external and internal mental demands during dispensing. External demands including interruptions and divided attention negatively impacted medication safety and employee well-being [2]. Busy and stressful working environments contribute significantly to errors. Error rates have been found to increase when health care professionals are distracted, depressed, stressed, inattentive, or inexperienced [3]. Stress was the most common reason for a clinical pharmacist to leave a job [4]. Pharmacy residents are clinical pharmacists in training. The impact of environmental factors on stress experienced by the pharmacy resident population is unknown. Similarly, little is known about a relationship between pharmacy residents' stress and medication errors. Therefore, we decided to publish the findings of Ph.D. research that was conducted in 2012. This may help lay the groundwork for future research in this area. The significance of perceived stress as well as negative affects levels in pharmacy residents was published [5]. This is a second part of the research which aimed to evaluate the impact of environmental factors, such as professional, situational and personal on pharmacy resident's stress. Another aim is to explore a relationship between residents' stress and medication errors.

\section{Stress and residency training}

The goals of pharmacy residency training are to enhance resident's general competencies in managing medication-use systems and to support optimal medication therapy outcomes for patients with a broad range of disease states. During their residency training, residents are responsible for managing and improving the medication-use process; providing evidencebased, patient-centered medication therapy management with interdisciplinary teams; exercising leadership and practice management; demonstrating project management skills; providing medication and practice-related education; and utilizing medical informatics [6]. The impact of the training environment on pharmacy residents is unknown. In contrast, environmental stress on medical residents during residency training is well documented. Specialties associated with frequent exposure to incurable or dying patients were considered high burnout specialties [7]. Some studies suggest that medical residents from different disciplines or different 
countries are alike in experiencing stress and burnout because they have similar stressful training environments [8-10]. One may assume that pharmacy residents may have similar stress. A literature search, however, failed to yield any studies exploring pharmacy residency training and stress. The outcome of this association is not known.

\section{Medication errors and stress}

Adverse drug events (ADEs) are one of the common medical errors that occur during the course of providing health care. Mistakes by pharmacists are a contributing factor to those ADEs. The errors could occur in the dispensing of drugs by pharmacists. Pharmacists' errors can be mechanical (preparation and processing of the prescription) or judgmental (counseling, screening or patient drug monitoring) [11]. In 2006, Institute of Medicine published a report "Preventing Medication Errors" which concluded that at least 1.5 million preventable ADEs cause harm in the United States each year. The report estimated that medication errors in hospitals alone cost $\$ 3.5$ billion a year [12].

The American Society of Health-System Pharmacists published guidelines on safe medication practices. Pharmacist must maintain a safe working environment, in order to minimize distractions and interruptions that could lead to medication errors [13]. Busy and stressful working environments contribute significantly to the errors [1]. Pharmacy residents often work long hours and have heavy workloads [5]. However, whether there is an association between pharmacy residents' stress and their medication errors remains unclear.

\section{Methods}

\section{Participants \& sampling method}

There were 2,321 pharmacy residency positions filled in 2011-2012 training year in the United States according to the National Matching Services [14]. A list of pharmacy residency programs in the United States including pharmacy residency directors and their contact information was retrieved from the Residency Directory of American Society of Health System Pharmacists web site which was publicly published [15]. An invitation email was sent out to ask the pharmacy directors to inform Pharmacy residents about a confidential and voluntary opportunity to participate in a study of resident stress via an anonymous online questionnaire survey. Pharmacy residents were provided a web link to the study questionnaire. A password was also provided to protect copyright content and prevent people who were not pharmacy residents from entering this study. Since the pharmacy residency training often started in July and ended in June of the following year, we aimed to collect data when the residents were at least past half way of their residency training year. Data collection started in February of 2012 and ended in March of 2012 when there was no participant entry to the online survey in 10 days. The study sample was drawn by a convenience sampling method.

\section{Sample size}

Using a sample size calculator for online survey from Raosoft, based on the population size, a sample size of at least 330 subjects was sufficient for the online questionnaire study with confidence level of $95 \%$, margin of error of $5 \%$ [16]. $G^{*}$ Power analysis ( $G^{*}$ Power version 3.2.1) was also used to determine a minimum sample size needed for each statistical test [17]. With power $=0.95$, alpha $=0.05$ and a moderate effect size $(\mathrm{f}=0.25)$, the minimum number of participants needed for the study was 210 . Therefore, the sample size estimate for participants was sufficient for the $\mathrm{G}^{*}$ Power analysis.

\section{Instruments}

The 10-item Perceived Stress Scale (PSS-10) was used to assess stress of the study subjects. The PSS-10 contains 10 questions with answers ranked using a Likert 5-point scale, from 0 to 4 . It assesses stressful experiences as well as responses to stress during the past month [18]. It was free to use. It was designed to measure the degree to which situations in one's life were appraised as stressful. It was also designed for target populations with at least a high school education level. The questions in the PSS-10 were designed to measure how unpredictable, uncontrollable and overloaded respondents find their lives [19].

Environmental stressors were adapted from a study by Eckleberry-Hunt and colleagues with permission from the authors [20]. In this study, the authors listed 32 burnout items that were commonly encountered in medical residency training based on available literature. A Likert 5-point scale ( 1 "does not apply" and 5 "strongly applies") was used in the study. Their validity and reliability were proven as there were statistically significant associations between these stressors, and anxiety, depression, burnout. In our study, those items were divided into eight environmental stressor groups: Time \& Workload, Support, Financial, Family, Personal, Clinical Rotation Challenge, Career and Health.

Self-reported medication errors included several factors that related to medication errors. Those factors likely contributed to medication errors that pharmacists frequently committed [2125]. Based on the mentioned literature, those factors were adapted for pharmacy residents. For consistency, a Likert 5-point scale was also used to measure the factors of self-reported medication errors from pharmacy residents. Participants answered questions focused on medication errors that occurred in the previous 3 months prior to administration of the survey.

\section{Statistical analysis}

The collected data were analyzed by using IBM SPSS version 19.0. Cronbach's alpha was used to analyze reliability of the environmental stressors, self-reported medication error, and perceived stress. Cronbach's alpha of all measured scores was found to be above unacceptable level $(>0.5)$. A Pearson Product Moment correlation was used to examine the correlation between perceived stress scores and selfreported medication errors. A multiple linear regression 
was conducted to predict perceived stress score from the environmental stressors. All findings were reconfirmed with non-parametric analyses. The study used a correlational method, not manipulating any variables.

\section{Results}

A total of 524 participants were included for data analysis in our cross-sectional study. The usable response rate was $22.5 \%$. Majority of participants were female $(75.4 \%)$ and single $(70.6 \%)$. More than $93 \%$ of participants were under 30 years old. Baseline demographics of pharmacy residents could be found in Table 1 [5].

A mean score of all pharmacy resident's perceived stress $(\mathrm{n}=524)$ was $19.06(\mathrm{SD} \pm 5.90)$. The stress scores ranged from 3.0 to 37.0. A mean score of PGY1 residents $(n=388)$ was $19.05(\mathrm{SD} \pm 5.96)$ and of PGY2 residents $(n=136)$ was 19.09 $(\mathrm{SD} \pm 5.77$ ) [5]. A difference in residency year did not have a significant effect on participants' perceived stress scores $(t$ $(522)=-0.0071, p=0.943)$. Mean scores of medication error factors are shown in Table 2. Each medication error factor score ranged from 1.0 to 5.0. Self-reported medication error score is a sum of those medical error factor scores.

Table 1. Baseline characteristics of the pharmacy residents.

\begin{tabular}{|c|c|c|}
\hline & Total (n) & $\%$ \\
\hline \multicolumn{3}{|l|}{ Gender } \\
\hline Male & 129 & 24.6 \\
\hline Female & 395 & 75.4 \\
\hline \multicolumn{3}{|l|}{ Age } \\
\hline $20-25$ & 216 & 41.2 \\
\hline $26-30$ & 273 & 52.1 \\
\hline 31-35 & 22 & 4.2 \\
\hline $36-40$ & 10 & 1.9 \\
\hline $40-45$ & 2 & 0.4 \\
\hline $46-50$ & 1 & 0.2 \\
\hline \multicolumn{3}{|l|}{ Pharmacy Residency Year } \\
\hline PGY1 Resident & 388 & 74.0 \\
\hline PGY2 Resident & 136 & 26.0 \\
\hline \multicolumn{3}{|l|}{ Marital Status } \\
\hline Single & 370 & 70.6 \\
\hline Married & 154 & 29.4 \\
\hline
\end{tabular}

Details of correlations of self-reported medication errors and perceived stress scores among pharmacy residents are shown in Table 3. The correlations between perceived stress score and self-reported medication errors score was statistically significant $(r=0.339, p<0.001)$. Higher perceived stress scores tended to associate with higher medication error scores. A subgroup analysis also showed a statistically significant correlation between perceived stress with medication error scores in each PGY1 $(r=0.374, p<0.001)$ and PGY2 $(r=0.232, p=0.007)$ pharmacy resident groups. A comparison of correlation statistics of the relation between perceived stress scores and medication error scores revealed no statistical difference between PGY1 and PGY2 pharmacy resident groups $(\mathrm{z}=1.56, p>0.05)$.

Mean and standard deviations of environmental items are shown in Table 4. Each environmental item score ranged from 1.0 to 5.0. A score of each environmental stressor is a sum of its related environmental items. A multiple linear regression was used to predict perceived stress score from the environmental stressors. The overall regression model predicting perceived stress score was statistically significant $\left(F(8,515)=73.52, p<0.001\right.$, Adjusted $\left.R^{2}=0.526\right)$. As shown in Table 5, the environmental stressors that were significant predictors of perceived stress are Time and Workload (Beta $=0.300, p<0.001)$, Support (Beta=0.141, $p=0.002$ ), Personal (Beta $=0.249, \quad p<0.001)$, Career $\quad$ Beta $=0.113$, $p=0.005)$ and Health $($ Bet $a=0.213, p<0.001)$. It indicated that pharmacy residents with a high environmental stressor score were more likely to have a high perceived stress score. The Financial, Family and Clinical Rotation Challenge stressors were not significant predictors $(p>0.05)$.

\section{Discussion}

It is important to emphasize that the correlation between pharmacy residents' perceived stress score and self-reported medication error is not a causal relationship. A difference in residency years did not have a significant effect on this correlation. This finding is noteworthy because prior to our study, there was no literature to examine this correlation in pharmacy residents. Only a few studies on stress, depression,

Table 2. Factors of self-reported medication errors.

\begin{tabular}{|l|c|}
\hline & Mean Score \pm SD \\
\hline Self-reported medication errors $(\mathbf{n = 5 2 4 )}$ & $12.52 \pm 5.50$ \\
\hline Made medication errors in past 3 months & $2.11 \pm 1.17$ \\
\hline Made medication errors which were not due to a lack of knowledge or inexperience & $2.05 \pm 1.15$ \\
\hline Pay little attention to warnings of potential drug interactions & $1.70 \pm 0.89$ \\
\hline Pay little attention to warnings of potential inappropriate frequency or dose for patient's condition & $1.69 \pm 0.90$ \\
\hline Pay little attention to warnings of potential contraindications & $1.68 \pm 0.89$ \\
\hline Pay little attention to detect medication errors on a patient's medication profile & $1.66 \pm 0.90$ \\
\hline Pay little attention to warnings of potential drug duplications & $1.64 \pm 0.84$ \\
\hline
\end{tabular}

Table 3. Correlations of self-reported medication errors and perceived stress scores.

\begin{tabular}{|c|c|c|}
\hline \multirow{2}{*}{ Perceived Stress PSS-10 } & \multicolumn{2}{|c|}{ Self-reported medication errors } \\
\cline { 2 - 3 } & $\mathbf{r}$ & $<$ \\
\hline All residents & 0.339 & $<0.001$ \\
\hline PGY1 & 0.374 & $<0.001$ \\
\hline PGY2 & 0.232 & $<0.01$ \\
\hline
\end{tabular}


Citation: Le HM, Young SD. Exploring the relationship between environmental stressors, pharmacy residents'stress and medication errors. J Psychol Cognition. 2017;2(3):192-197.

Table 4. Scores of environmental stressors.

\begin{tabular}{|c|c|}
\hline Environmental Groups & $\begin{array}{l}\text { Mean Score } \\
\quad \pm \text { SD }\end{array}$ \\
\hline Time and Workload Stressors & $23.15 \pm 5.89$ \\
\hline Not enough time in the day & $4.18 \pm 1.04$ \\
\hline Excessive paperwork or documentation & $3.41 \pm 1.18$ \\
\hline Work overload inhibits learning & $3.40 \pm 1.39$ \\
\hline Too many work demands & $3.28 \pm 1.27$ \\
\hline Difficulty staying on schedule & $3.21 \pm 1.21$ \\
\hline Pressure to teach/do "extra" projects & $3.17 \pm 1.30$ \\
\hline Lack of control over schedule & $2.52 \pm 1.31$ \\
\hline Support Stressors & $22.99 \pm 9.04$ \\
\hline Variability in preceptor expectations & $2.82 \pm 1.34$ \\
\hline Fairness of performance evaluation system & $2.45 \pm 1.22$ \\
\hline Lack of recognition of my accomplishments & $2.37 \pm 1.28$ \\
\hline Inadequate feedback from director/preceptor & $2.26 \pm 1.22$ \\
\hline Lack of regular forum to discuss concerns & $2.18 \pm 1.26$ \\
\hline Inadequate supervision of residents & $1.95 \pm 1.15$ \\
\hline Inattentive/non-supportive preceptor & $1.90 \pm 1.14$ \\
\hline Preceptor favoritism, bias & $1.79 \pm 1.18$ \\
\hline Inattentive/non-supportive program director & $1.79 \pm 1.16$ \\
\hline Lack of resources to do my job & $1.76 \pm 0.98$ \\
\hline Poor support staff & $1.71 \pm 1.00$ \\
\hline Family Stressors & $10.24 \pm 3.32$ \\
\hline $\begin{array}{l}\text { Conflicting responsibilities between home, family, and } \\
\text { work }\end{array}$ & $3.56 \pm 1.27$ \\
\hline Guilt about never having enough time for family & $3.37 \pm 1.36$ \\
\hline Family conflict & $2.14 \pm 1.21$ \\
\hline Worry over child care arrangements & $1.16 \pm .65$ \\
\hline Financial Stressors & $6.07 \pm 2.69$ \\
\hline Not having enough money & $3.10 \pm 1.43$ \\
\hline Too much debt & $2.97 \pm 1.54$ \\
\hline Personal Stressors & $18.43 \pm 3.68$ \\
\hline $\begin{array}{l}\text { Lack of time to exercise, take care of myself, and do things } \\
\text { I enjoy }\end{array}$ & $4.22 \pm 1.01$ \\
\hline Being a perfectionist & $4.06 \pm 0.86$ \\
\hline Lack of sleep & $3.79 \pm 1.96$ \\
\hline Guilt about never having enough time for work & $2.93 \pm 1.37$ \\
\hline Being a pessimist & $2.14 \pm 1.01$ \\
\hline My own bad habits & $1.28 \pm 0.68$ \\
\hline Clinical Rotation Challenge Stressors & $9.50 \pm 3.03$ \\
\hline Difficult and complicated patients & $3.20 \pm 1.20$ \\
\hline Lack of control over hospital processes & $2.38 \pm 1.22$ \\
\hline Lack of control over my training & $2.22 \pm 1.39$ \\
\hline Poor relationships with colleagues & $1.69 \pm 0.97$ \\
\hline Health Stressors & $12.69 \pm 3.83$ \\
\hline Feel exhausted by end of day & $4.03 \pm 1.08$ \\
\hline Feeling tired most of the day & $3.59 \pm 1.23$ \\
\hline Feeling a decline in physical health & $3.12 \pm 1.40$ \\
\hline Home sick more often past 3 months & $1.95 \pm 1.33$ \\
\hline Career Stressors & $10.21 \pm 3.37$ \\
\hline Difficulty staying organized & $2.88 \pm 1.20$ \\
\hline Not wanting to go to work in the morning & $2.47 \pm 1.28$ \\
\hline Worry about malpractice suits and litigation & $1.65 \pm 0.93$ \\
\hline Boredom in my job & $1.61 \pm 0.92$ \\
\hline Regret over chosen career & $1.60 \pm 1.02$ \\
\hline
\end{tabular}

and medication errors with a similar finding are conducted in a different population: medical residents. Self-perceived medical errors were commonly reported among internal medicine residents and were associated with personal distress [26]. Personal distress was also associated with increased
Table 5. Environmental stressors contributing to stress scores.

\begin{tabular}{|l|c|c|c|}
\hline \multirow{2}{*}{$\begin{array}{l}\text { Environmental } \\
\text { stressors }\end{array}$} & \multicolumn{3}{|c|}{ Perceived Stress PSS-10 } \\
\cline { 2 - 4 } & $\begin{array}{c}\text { Standardized Beta } \\
\text { Coefficients }\end{array}$ & $\boldsymbol{t}$ & $\boldsymbol{p}$ \\
\hline Time and Workload & 0.300 & 6.59 & $<0.001$ \\
\hline Personal & 0.249 & 5.76 & $<0.001$ \\
\hline Health & 0.213 & 5.05 & $<0.001$ \\
\hline Support & 0.141 & 3.16 & 0.002 \\
\hline Career & 0.113 & 2.79 & 0.005 \\
\hline Family & -0.062 & -1.73 & 0.085 \\
\hline $\begin{array}{l}\text { Clinical Rotation } \\
\text { Challenge }\end{array}$ & -0.070 & -1.59 & 0.113 \\
\hline Financial & -0.031 & -0.93 & 0.352 \\
\hline
\end{tabular}

odds of future self-perceived errors [27]. Our study was the first to establish a relationship between pharmacy residents' stress and medication error. Further research may be needed to explore this relationship to see if there is a causal relationship.

For environmental stressors, our study is exploratory because there is no prior research regarding the interaction between environmental stressors and pharmacy residents. Three items in the Support stressor that residents gave high scores were 'Variability in preceptor expectations', Fairness of performance evaluation system' and 'Lack of recognition of my accomplishments'. Support is an important factor that protects individuals from stress [26]. In our opinion, lacking support and recognition from the residency program, residents could experience negative thinking that may contribute to stress. Residency programs can tackle this issue by establishing expectations for each rotation and acknowledging areas the resident excels in during regular feedback sessions. For Personal stressor, residents identified three significant items: 'Lack of time to exercise, take care of myself, and do things I enjoy', 'Being a perfectionist', and 'Lack of sleep'. Lacking time for one's self could be a result from working too much or having a heavy workload. It is known in literature that lack of sleep can be associated with stress and depression [26,27]. Pharmacy residents who identify themselves as perfectionists probably worry about work or projects more than others. The residents gave higher scores on two items in Career stressor: 'Difficulty staying organized', and 'Not wanting to go to work in the morning'. This may be due to having a heavy workload or long duty hours.

A contribution of Time and Workload stressor is significant to resident's stress. The residents gave higher scores on four items 'Not enough time in the day', 'Excessive paperwork or documentation', 'Work overload inhibits learning', and 'Too many work demands'. In our opinion, teaching the residents to manage time efficiently may help residents reduce stress. On Health stressor, residents gave higher marks on three items: 'Feeling exhausted by end of day', 'Feeling tired most of the day' and 'Feeling a decline in physical health'. Physical exhaustion could reduce resident's ability to cope with stressors and have negative effects on their psychological health $[28,29]$. Residency programs can assist 
residents by stressing the importance of work-life balance, stress-management, and maintaining a healthy lifestyle [30].

Based on our extensive literature search, our study is the first to provide understanding of the correlation between stress and medication error as well as the contribution of environment factors to stress in U.S. pharmacy resident population.

There are several limitations to the study. This is a cross-sectional study; therefore, it does not draw any causal relationships between stress and medication errors. The convenience sampling may not be representative of the entire population of pharmacy residents. The questionnaire survey has its limitations since it depends on the subjectivity of each individual who evaluated their own stress. In the same situation, two people might respond in different ways and provide different answers even if validated questionnaires are used. All cross-sectional studies, by the time of publication, only provide a snapshot of the past and it may not be representative for the present.

\section{Conclusion}

There is a relationship between stress levels and medication errors reported by pharmacy residents. Further research may be needed to help validate this notion. Pharmacy residents identified many environmental stressors that may contribute to their stress during their residency training: Time and Workload, Personal, Health, Support and Career stressors. The results of this study could assist residency program directors and preceptors in providing better support through helping residents manage time effectively, providing preceptor availability for difficult patient cases, and discussing realistic expectations and work-life balance with residents.

\section{Key Points}

- Pharmacy residents who report higher levels of perceived stress also report higher medication errors.

- Environmental stressors such as Time and Workload, Support, Personal; Career and Health significantly contribute to resident's perceived stress.

- Residency programs can provide assistance by lending support to residents, helping them manage time effectively and discussing work-life balance.

\section{References}

1. Mott AD, Doucette RW, Gaither AC, et al. Pharmacists' attitudes toward work life: Results from a national survey of pharmacists. J Am Pharm Assoc. 2004;44(3):326-36.

2. Holden RJ, Patel NR, Scanlon MC, et al. Effects of mental demands during dispensing on perceived medication safety and employee well-being: A study of workload in pediatric hospital pharmacies. Res Social Adm Pharm. 2010;6(4):293-306.

3. McDowell S, Ferner H, Ferner RE. The pathophysiology of medication errors: How and where they arise. Br J Clin Pharmacol. 2009;67(6):605-13.

4. Goodwin SD, Kane-Gill SL, Ng TM, et al. American college of clinical pharmacy white paper: Rewards and advancements for clinical pharmacists. Pharmacotherapy. 2010;30(1):68e-85e

5. Le HM, Young SD. Evaluation of stress experienced by pharmacy residents. Am J Health Syst Pharm. 2017;74(8):599-604.

6. https://www.ashp.org/pharmacy-practice/policypositions-and-guidelines/browse-by-topic/medicationtherapy-and-patient-care/

7. Olkinuora M, Asp S, Juntunen J, et al. Stress symptoms, burnout and suicidal thoughts in Finnish physicians. Soc Psychiatry Psychiatr Epidemiol. 1990;25(2):81-6.

8. Gopal R, Glasheen JJ, Miyoshi TJ, et al. Burnout and internal medicine resident work-hour restrictions. Arch Intern Med. 2005;165(22):2595-600.

9. Linzer M, Visser MR, Oort FJ, et al. Predicting and preventing physician burnout: Results from the United States and Netherlands. Am J Med. 2001;111(2):170-5.

10. Panagopoulou E, Montgomery A, Benos A. Burnout in internal medicine physicians: Differences between residents and specialists. Eur J Intern Med. 2006;17(3):195-200.

11. Abood RR. Errors in pharmacy practice. US Pharmacists. 1996;21(3):122-30.

12. Aspden P, Wolcott JA, Bootman JL, et al. Preventing medication errors. National Academy Press, Washington, DC. 2006 .

13. American Society of Hospital Pharmacists. ASHP guidelines on preventing medication errors in hospitals. Am J Hosp Pharm. 1993;50(2):305-14.

14. http://www.natmatch.com/ashprmp

15.https://accred.ashp.org/aps/pages/directory/ residencyprogramsearch.aspx

16. http://www.raosoft.com/samplesize.html

17. http://www.gpower.hhu.de/en.html

18. Cohen S, Kamarck T, Mermelstein R. A global measure of perceived stress. J Health Soc Behav. 1983;24:386-96.

19. Cohen S, Tyrrell AD, Smith PA. Negative life events, perceived stress, negative affect and susceptibility to the common cold. J Pers Soc Psychol. 1993;64(1):131-40.

20. Eckleberry-Hunt J, Lick D, Boura J, et al. An exploratory study of resident burnout and wellness. Acad Med. 2009;84:269-77.

21. Aspden P, Wolcott JA, Bootman JL, et al. Preventing medication errors. National Academy Press, Washington, DC. 2006. 
Citation: Le HM, Young SD. Exploring the relationship between environmental stressors, pharmacy residents'stress and medication errors. J Psychol Cognition. 2017;2(3):192-197.

22. Brown NJ, Barnes LC, Beasley B, et al. Effect of pharmacists on medication errors in an emergency department. Am J Health Syst Pharm. 2008;65(4):330-3.

23. Budnitz DS, Pollock DA, Weidenbach KN, et al. National surveillance of emergency department visits for outpatient adverse drug events. JAMA. 2006;296:1858-66.

24. Kohn LT, Corrigan JM, Donaldson MS. To Err is human: Building a safer health system. National Academy Press, Washington, DC. 1999;26-65.

25. Santell JP, Cousins DD. Medication errors involving wrong administration technique. Jt Comm J Qual Patient Saf. 2005;31:528-32.

26. West PC, Huschka MM, Novotny JP, et al. Association of perceived medical errors with resident distress and empathy. JAMA. 2006;296(9):1071-8.

27. Fahrenkopf AM, Sectish TC, Barger LK, et al. Rates of medication errors among depressed and burnt out residents: Prospective cohort study. BMJ. 2008;336:488-91.

28. Sun Han K, Kim L, Shim I. Stress and sleep disorder. Exp Neurobiol. 2012;21(4):141-50.

29. Cohen S, Tyrrell AD, Smith PA. Negative life events, perceived stress, negative affect and susceptibility to the common cold. J Pers Soc Psychol. 1993;64(1):131-40.

30. Dabrow S, Russell S, Ackley K, et al. Combating the stress of residency: One school's approach. Acad Med. 2006;81:436-9.

\section{*Correspondence to:}

Hung M Le

PharmD, PhD

Clinical Pharmacy Specialist

Department of Pharmacy

VA Texas Valley Coastal Bend Health Care System 2601 Veterans Drive (119 HCC)

Harlingen

Texas 78550

USA

E-mail: lhung2006@gmail.com 